\title{
Корпоративное управление и операционная эффективность российских компаний
}

\author{
Степанова А.Н. ${ }^{6}$, Кузьмин С.А. ${ }^{7}$
}

В этой статье изучается влияние качества корпоративного управления в российских компаниях на их операчионную эффективность, измеренную граничными методами (DEA и SFA). Качество корпоративного управления фиксируется с помощью оригинального рейтинга корпоративного управления, методология которого раскрывается в данной работе. На выборке из 54 российских компаний авторы тестируют предложенную модель операчионной эфрективности и выявляют высокий уровень значимости качества корпоративного управления.

$J E L: G 32, G 34$

Ключевые слова на русском: корпоративное управление, эффективность, развивающиеся рынки, DEA, структура собственности

\section{Введение}

С конца 1990-х годов тема корпоративного управления стала очень популярной в России, после того как страна ощутила неоценимую роль частного сектора в развитии экономики. К сожалению, многие российские компании занимаются оптимизацией корпоративного управления больше для создания положительного имиджа и репутации, нежели для того, чтобы заручиться большей поддержкой акционеров, быть более устойчивым в разгар финансовых кризисов и иметь больше возможностей для доступа к капиталу.

Успешное корпоративное управление минимизирует риск оппортунистического поведения и самоуправства со стороны менеджеров. В совокупности с успешным рискменеджментом и внутренним контролем ответственное поведение менеджеров создает компании дополнительную устойчивость в разгар потрясений и финансовых кризисов. К примеру, привязка зарплаты членов совета директоров к результатам компании может создать благоприятную атмосферу в коллективе и настроить менеджеров на хороший рабочий лад. При хорошем корпоративном управлении также усовершенствуется процесс принятия решений. Когда правильно построенная внутренняя структура компании позволяет менеджерам, директорам и акционерам лучше понимать свои роли и обязанности, финансовые решения принимаются быстрее, общая работа идет слаженнее и эффективнее. Гомперс, Иши и Метрикс (Gompers et al., 2001) в своей работе также подтверждают, что высококачественное корпоративное управление снижает затраты на привлечение капитала и стимулирует рост прибылей.

В России традиции корпоративного управления, которые появились сравнительно недавно, формируются под давлением европейских и американских традиций корпоративного управления благодаря огромному количеству экспатов в топ-менеджменте крупных российских корпораций и банков, а также благодаря присутствию на российском рынке финансовых услуг глобальных инвест-банков и консалтинговых компаний. Немалую роль играет тенденция к получению образования в Европе и США. Тем не менее сегодняшние традиции корпоративного управления в России во многом обусловлены

\footnotetext{
${ }^{6}$ Канд. эконом. наук, доцент кафедры экономики и финансов фирмы НИУ ВШЭ.

${ }^{7}$ Аналитик дирекции по структурированным кредитным продуктам «Альфа-Банка».
} 
характером бизнес-среды, в которой они развиваются. Так, нельзя забывать о том, что менее 20 лет назад произошел процесс приватизации, сформировавший первоначальную структуру собственности российских компаний. Остановимся на нескольких ярких особенностях финансовой архитектуры российских компаний.

Концентрированная структура собственности

С начала 1990-х большинство крупных предприятий в России контролируется либо единственным акционером, либо маленькой группой очень крупных акционеров. Если такая особенность объяснима в компаниях, имеющих дело с нефтью или газом (руководство страны всегда негативно относилось к распылению прав собственности в стратегических отраслях), то для отрасли коммуникаций, металлургии и химической промышленности подобная структура собственности зачастую мешает развитию бизнеса.

Более того, компании с концентрированной собственностью нередко ущемляют в правах миноритарных акционеров. В качестве живого примера может служить недавний скандал между банком ВТБ и его миноритариями ${ }^{8}$, который существенного ударил по репутации «второго» банка страны. Доминирование собственников-инсайдеров и слабая защита внешних инвесторов всегда являлись одной из главных причин низкого уровня развития российского рынка капитала.

\section{Неповоротливые холдинговые структуры}

Российская действительность такова, что небольшое число бизнес-агломераций в форме холдингов контролируют огромное множество компаний в различных отраслях, тем самым делая их непрозрачными для внешних акционеров и инвесторов. В холдинговых структурах сложнее контролировать нарушения в области дискриминации прав миноритарных акционеров.

Слабое разграничение между собственниками и контролирующими органами

В большинстве случаев в российских компаниях мажоритарные акционеры занимают большое число кресел в совете директоров, тем самым полностью лишая фирму объективной контролирующей структуры. Это тесно связано с низким уровнем независимости в российских советах директоров. Согласно ряду исследований, введение дополнительного независимого директора в совет существенно повышает корпоративную эффективность в развивающихся странах (Ivashkovskaya, Stepanova, 2011).

\section{Реорганизация бизнеса}

Еще одной отличительной российской особенностью является частое изменение структуры и стратегии ведения бизнеса холдингами и крупными бизнес-группами. Подобные реорганизации, даже носящие неконфликтный характер, порой создают хаос и сумятицу среди остальных инвесторов и некрупных акционеров. Как пример, можно взять дробление компании РАО «ЕЭС России» на многочисленные более мелкие фирмы, которые сложно оценить с точки зрения потенциального роста и финансовой устойчивости.

\section{Неопытный совет директоров}

В российских компаниях часто нарушается структура управления. Так, председатели совета часто выходят на контакт и лично ведут переговоры с ведущими акционерами, тем самым постоянно обходя внутреннюю систему контроля компании. Кроме того, в совет

\footnotetext{
${ }^{8}$ http://www.rbcdaily.ru/2010/01/27/finance/454822.
} 
директоров часто входят родственники или близкие друзья мажоритариев компании и других людей с высоким уровнем переговорной силы. Это, безусловно, негативно влияет на качество органов внутреннего контроля, и проблема совершенствования корпоративного управления встает еще более остро.

Таким образом, очевидны несовершенства принятой в России системы корпоративного управления. Нужно ли бороться с этими точками неэффективности? Есть ли необходимость в этом? Изменит ли более совершенная система корпоративного управления эффективность компании? На эти вопросы мы попытались ответить в этой статье.

Работа построена следующим образом. В следующей части статьи предложен обзор предшествующих исследований, посвященных взаимосвязи корпоративного управления, структуры собственности и операционной эффективности компании. Далее мы рассмотрим гипотезы и модель исследования, после чего перейдем к методологии составления расчетного рейтинга корпоративного управления. В последней части статьи представлены выводы и потенциальные вопросы для дальнейших дискуссий.

\section{Обзор литературы}

В данной работе мы основываемся на следующих определениях корпоративного управления. Четкое определение корпоративного управления дает в своей работе Тироль (Tirole, 2001): «Корпоративное управление - это такое построение институтов, которое вынуждает менеджмент заботиться о благосостоянии акционеров». Уильямсон в своей статье отметил, что простая структура корпоративного управления наносит вред большим корпорациям, так как неспособна справиться со сложными задачами (Williamson, 1987), а Хилб и вовсе обозначил новый вектор развития корпоративного управления, который согласуется с задачами крупных компаний в XXI веке (Hilb, 2006):

- Внедрение системы корпоративного управления должно быть специфично для каждой компании.

- Стратегическое развитие компании должно быть главной функцией правления.

- Большое внимание должно уделяться выбору и развитию членов совета директоров.

- Должен осуществляться мониторинг результатов с позиции акционеров, клиентов, сотрудников и обычных людей.

Огромное количество работ посвящено выявлению влияния корпоративного управления на операционную эффективность деятельности компании, однако большинство этих работ изучает значимость корпоративного управления для эффективности, измеренной одномерными показателями (уровнем производительности, долей операционных расходов, etc.).

Можно выявить четыре блока работ, изучающих взаимосвязь корпоративного управления и операционной эффективности в зависимости от метода оценивания. Первый блок работ оценивает зависимость путем построения LS регрессий. Другим методом является конструирования индекса общей факторной производительности (ТFР). Тем не менее наиболее применяемыми остаются оценка с помощью построения стохастической границы эффективности (SFA), а также метод DEA (Data Envelopment Analysis). Каждый способ имеет свои достоинства и недостатки, о которых мы поговорим позже.

Остановимся на первом блоке работ, рассматривающем влияние различных финансовых и нефинансовых показателей на операционную эффективность компании с помощью тестирования регрессионных моделей. Результаты таких работ зависят от выборки и от способа измерения операционной эффективности.

В ряде работ по развивающимся рынкам было доказано, что среди нефинансовых факторов на производительность труда влияют концентрация собственности (Xu, Wang, 1997), доля государства и собственность инсайдеров (Frydman et al., 1997). Согласно результатам ряда работ (Frydman et al., 1997), собственность иностранных акционеров часто оказывается незначима для операционной эффективности, оказывая значимое влияние, как 
правило, на стратегическую эффективность. Частные собственники могут существенно повысить темп роста производства компании по сравнению с государственными собственниками. Фирмы с внешними собственниками часто имеют более высокую производительность по сравнению с компаниями, контролируемыми инсайдерами.

Второй блок работ измеряет техническую эффективность фирм, которая достигается путем максимизации выпуска с использованием оптимального количества факторов производства. Согласно результатам ряда работ, на операционную эффективность компаний, измеренную с помощью индекса технической эффективности, из нефинансовых факторов влияет уровень конкуренции и доля государственной собственности в компании (Brown, Earle, 2000; Gumbau-Albert, Maudos, 1998).

Однако оба вышеперечисленных подхода имеют ряд недостатков, а именно: ни уровень производительности в конкретный момент времени, ни технический индекс эффективности реально не учитывают огромного спектра управленческих факторов, позволяющих поддерживать или наращивать уровень операционной эффективности компании в целом. Частично сгладить этот недостаток позволяет комплексный подход к оценке операционной эффективности компании, включающий построение стохастической границы эффективности (SFA) и метод DEA.

В ряде работ подтверждается возможность значимого влияния качества корпоративного управления и уровня финансового рычага на операционную эффективность компаний на развивающихся рынках, измеренную с помощью стохастических границ (Piesse, Khatri, 2002; Liao et al., 2010).

Актуальность изучения операционной эффективности и корпоративного управления на развивающихся рынках капитала подтверждаются рядом отличительных особенностей развивающихся экономик, выделенных в статье Фридмана (Frydman et al., 1997). Для того чтобы понять, почему различные типы собственников по-разному влияют на эффективность компаний, Фридман обозначил ряд факторов, свойственных переходным экономикам:

- Во всех переходных экономиках на рынке оперирует огромное число как государственных, так и приватизированных компаний. Это делает возможным глубокое и детальное сравнение их эффективности и достигнутых результатов.

- Как правило, в переходных экономиках любые формы собственности находятся в начале своей эволюции, со множеством неэффективных собственников, что упрощает анализ сравнительной эффективности.

- Широкое поле для исследований дают также следующие факторы: защищенность многих предприятий в переходных экономиках от внешней конкуренции; неразвитость фондовых рынков; институты, осуществляющие корпоративное управление, крайне неэффективны в проведении внутреннего контроля компаний.

- Большая концентрация собственности. Несмотря на то что во многих компаниях Центральной и Восточной Европы существует разделение владельцев и менеджеров, зачастую возникают серьезные агентские проблемы.

- Общая нестабильность и высокий уровень неопределенности в переходных экономиках побуждают владельцев искать какие-то новые инновационные пути развития, а это, в свою очередь, втягивает собственников в активное управление предприятием.

Таким образом, основываясь на результатах работ прошлых лет, в работе были выдвинуты следующие гипотезы:

1. Увеличение доли государства негативно влияет на операционную эффективность компании.

2. Увеличение доли собственности у совета директоров негативно влияет на операционную эффективность компании.

3. Увеличение доли менеджмента положительно влияет на операционную эффективность компании.

4. Увеличение доли миноритариев положительно влияет на операционную 
эффективность компании.

5. Увеличение доли крупнейшего акционера отрицательно влияет на операционную эффективность компании.

Однако тестирование данных гипотез в отдельности привело бы нас к построению стилизованных моделей, тогда как нам интересен в данном случае комплексный подход. Для реализации комплексного подхода на основании данных гипотез авторами был предложен индекс корпоративного управления, принимающий во внимания все перечисленные аспекты, а также разработана модель влияния качества корпоративного управления на операционную эффективность.

\section{Методология исследования}

В данной работе мы использовали граничный метод DEA с целью измерения операционной эффективности российских компаний. В большинстве случаев метод DEA используется для оценки эффективности компаний, производящих какой-либо продукт. Обычные статистические тесты сравнивают эффективность производителей со средним значением по отрасли, тогда как в методе DEA сравнение происходит с «лучшим» возможным экономическим агентом.

DEA - непараметрический метод определения эффективности предприятия. Соответственно, при подсчетах не нужно определять производственную функцию, функцию издержек или прибылей. Также метод DEA при подсчете операционной эффективности использует метод мультипликаторов Лагранжа, а не LS регрессии, как в остальных методах. Однако самое важное то, что тест DEA по своей натуре не подразумевает использования статистических методов, поэтому финальные результаты не содержат стандартных ошибок. Любое отклонение от границы порождает неэффективность, что делает невозможным существование случайных шоков. Этот факт отличает метод DEA, в частности, от метода SFA, где стохастическая граница может сдвигаться под влиянием случайных шоков и ошибок.

В данной работе было решено использовать метод DEA по следующим причинам. Вопервых, из-за маленького размера выборки могут возникнуть проблемы при неверном определении формы производственной функции. Метод DEA не привязан к определению ее функциональной формы, что позволяет избежать смещенности в оценках эффективности. Во-вторых, DEA концентрируется на подсчитанных наиболее эффективных производственных границах, а не делает упор на предпосылках свойств производственных функций, как в анализе SFA. Наконец, DEA позволяет посчитать средневзвешенное значение коэффициентов технической эффективности групп компаний, сгруппированных по отрасли, типу собственника и т.д.

Сводная таблица переменных, использовавшихся в данном исследовании для нахождения коэффициентов технической эффективности методом DEA, представлена ниже.

Таблица 1

Переменные, использовавшиеся при подсчете коэффициентов эффективности

\begin{tabular}{c|c}
\hline & Зависимая переменная \\
\hline & ЕBITDA/Sales \\
1 & Объясняюшие переменные \\
2 & Labor cost $/ \$ \mathrm{mln}$ \\
3 & Material cost $/ \$ \mathrm{mln}$ \\
4 & Depreciation $/ \$ \mathrm{mln}$ \\
5 & BV Capital $/ \$ \mathrm{mln}$ \\
6 & \# employees \\
\hline
\end{tabular}


Для расчета коэффициентов технической эффективности, была использована программа $\mathrm{DeaOS}^{9}$, которая рассчитывает эффективность, решая задачу линейного программирования (см. результаты расчетов в Приложении 1). $\min \Theta$,

(1)

$$
\begin{array}{ll}
\text { s.t. } & Y \lambda \geq Y_{0}, \\
& \Theta X_{0}-X \lambda \geq 0, \\
& \lambda \geq 0
\end{array}
$$

где $\lambda$ - доля производителей, которые входят в корзину виртуальных производителей для каждого агента;

$X$ и $Y$ - зависимые и объясняющие переменные виртуального продюсера;

$\theta$ - операционная эффективность компании.

Первое ограничение в задаче означает то, что виртуальный производитель должен производить, по крайней мере, столько же товаров, сколько и реальный. Второе ограничение показывает, насколько меньше ресурсов необходимо виртуальному производителю для выпуска товара.

Далее, после подсчета коэффициентов эффективности для каждой фирмы, приступим ко второму шагу - построение регрессии следующего типа:

(2) $E F F=a(0)+a(1) B O D+a(2) M A N+a(3) G O V+a(4) M I N+a(5) M A X S H A R+a(6) C G I$,

где $E F F$ - коэффициент эффективности;

$B O D$ - суммарный пакет акций, принадлежащий членам совета директоров;

$M A N$ - пакет акций, принадлежащий менеджерам компании;

$M I N$ - пакет акций, принадлежащий миноритарным акционерам;

$M A X S H A R$ - пакет акций, принадлежащий крупнейшему акционеру;

$C G I$ - индекс корпоративного управления.

К сожалению, метод DEA работает на построении экстремумов, поэтому любой «шум», такой, например, как ошибка измерения, может представлять серьезную проблему и вылиться в смещенности коэффициентов приведенной выше регрессии. Для того чтобы избавиться от этой проблемы и существенно повысить объясняющую силу регрессии, было решено параллельно с обычным DEA-тестом провести SFA. SFA отличается тем, что два ограничения, приведенные в формуле (1), будут выполняться только с вероятностью $\alpha$ (Fethi et al., 2001). Таким образом, наиболее эффективные производственные единицы будут располагаться не на границе эффективности, как в обычном DEA, а в некой зоне вокруг границы, которая отражает доверительный интервал, показывающий вероятностную картину распределений эффективности производственной единицы. Граница эффективности (SFA) через центр площадей доверительных интервалов, и неизбежно некоторые производственные единицы будут находиться выше границы, что будет означать эффективность выше единицы, или, другими словами, суперэффективность (см. Приложение 2).

Далее перейдем к построению оригинального индекса корпоративного управления. При составлении индекса корпоративного управления были использованы отчеты компаний, база данных Factiva $^{10}$ и веб-сайт, специализирующийся на корпоративном управлении в России ${ }^{11}$. К сожалению, объем данной статьи не позволяет нам в полной мере раскрыть выбор структуры индекса корпоративного управления. Как известно, наиболее популярными индексами, связанными с механизмом корпоративного управления, считаются индексы агентства S\&P: индекс прозрачности (transparency index) и собственно индекс корпоративного управления (GAMMA index). Однако оба эти индекса являются, в отличие от кредитных рейтингов, закрытой платной услугой, и, соответственно, небольшой процент компаний рейтингован. Поэтому мы изучили опыт развивающихся стран по составлению расчетного индекса корпоративного управления на основе открытых данных (Gompers et al.,

\footnotetext{
${ }^{9}$ http://www.deaos.com.

${ }^{10} \mathrm{http}: / /$ factiva.com.

${ }^{11} \mathrm{http}: / /$ www.corp-gov.org.
} 
2003; Khanna et al., 2001; Klapper, Love, 2002; Ananchotikul, 2007). Ряд подобных индексов строится методом скоринга, например, каждое оппортунистическое действие менеджера увеличивает его значение на 1 (Gompers et al., 2003). Другие основываются на результатах исследования опросников (Khanna et al., 2001).

В большинстве своем индексы разбиваются на подиндексы, среди которых наиболее ярко выявляются налоговая открытость, раскрытие отчетности, независимость совета директоров, открытость совета директоров, соблюдение прав акционеров, социальная ответственность, дисциплина и др. Индекс, предложенный авторами для российских компаний, основан на структуре индекса для компаний Таиланда (Ananchotikul, 2007). Однако произведен ряд модификаций, упростивших индекс, с учетом вышеупомянутых гипотез.

В результате авторы решили оставить четыре пункта в индексе:

- Конфликт интересов между акционерами.

- Обязанности совета директоров.

- Права акционеров.

- Раскрытие информации.

Полностью структура индекса представлена в Приложении 4.1, а значения, полученные в результате применения методологии, - в Приложении 4.2.

\section{Выборка и результаты}

Для выяснения зависимости между структурой собственности и эффективностью компаний были изначально взяты 54 компании, торгующиеся на бирже ММВБ за 2007 год. Этот год был выбран исходя из того, что за этот период имеются данные у всех этих компаний, а также из-за того, что эти данные отражают докризисный период. Поскольку сейчас все компании рапортуют о восстановлении докризисных уровней операционных показателей, авторы посчитали нелогичным использовать данные за 2008-2009 годы, так как они хуже отражают сегодняшние реалии, а данные за 2010-2011 годы по большинству компаний просто отсутствуют.

Большинство данных были взяты из базы данных, разработанной в лаборатории корпоративных финансов ${ }^{12}$, а также с помощью отчетов компаний, и базы данных Factiva. Выборка покрывает все основные отрасли индустрии, начиная от нефтяной отрасли и заканчивая ретейлом.

Оценка эмпирической модели была произведена с помощью метода Тобита, поскольку объясняющие переменные колеблются в диапазоне от нуля до единицы. Представим результаты нашей оценки в виде таблицы (полный отчет см. в Приложении 3 ).

Таблица 2

Оценка регрессии методом Тобита. Зависимая переменная - операционная эффективность компании (DEA), независимые переменные: BOD, GOV, MAN, MAXSHAR, MIN, CGI.

\begin{tabular}{l|ll}
\hline $\begin{array}{c}\text { Объясняющзая } \\
\text { переменная }\end{array}$ & \multicolumn{1}{|c}{ Коэффициент } & \multicolumn{1}{c}{$z$-статистика } \\
\hline BOD & $-0,43^{*}$ & $-1,62$ \\
GOV & 0,1 & 0,71 \\
MAN & $0,3 * *$ & 2,1 \\
MAXSHAR & $0,52^{* * *}$ & 3,6 \\
MIN & $0,88^{* * *}$ & 3,41 \\
CGI & $0,37 * * *$ & 2,77 \\
\hline
\end{tabular}

*, ** и *** обозначают значимость на 10\%-ном, 5\%-ном и $1 \%$-ном уровне соответственно.

\footnotetext{
${ }^{12}$ Официальный сайт Лаборатории корпоративных финансов: http://www.cfcenter.ru.
} 
Мы видим, что относительно знаков коэффициентов не подтвердилась две гипотезы касательно максимальной доли акционеров и доли государства в компании. Тем не менее незначимым на 10\%-ном уровне оказался только коэффициент, связанный с долей государства. Общие выводы можно сделать следующие:

- Увеличение доли акций у членов совета директоров однозначно снижает операционную эффективность компаний, поскольку совет директоров начинает больше контролировать менеджмент и уделять меньше времени стратегическому планированию, из чего вытекают неоптимальные инвестиционные проекты и, как следствие, снижение эффективности.

- Увеличение государственного участия в российских компаниях, казалось бы, должно отрицательно сказаться на операционной эффективности, но незначимость этого коэффициента говорит о том, что госкомпании стараются принимать современные стратегии ведения бизнеса и пропасть между эффективностью частных и государственных компаний резко снизилась к 2007 году.

- Увеличение доли крупнейшего собственника в теории имеет неопределенный эффект на операционную эффективность. С одной стороны, в своей статье Lazareva, Rachinskiy, Stepanov (2007) авторы говорят, что увеличение доли крупнейшего акционера позволяет совету директоров больше времени уделять выработке стратегии. С другой стороны, усиление концентрации собственности может привести к тому, что будут приниматься выгодные для собственника, но неэффективные инвестиционные проекты. В российских реалиях концентрация собственности помогает защитить предприятие от издержек, связанных с конфликтами акционеров, и поэтому увеличение доли крупнейшего собственника ведет к увеличению эффективности.

- Зависимость между долей миноритариев и эффективностью получилась положительной и очень значимой. Сегодняшнее российское корпоративное законодательство не позволяет миноритариям активно отстаивать свои права, максимум - к ним могут иногда прислушаться, чтобы создать видимость компании с хорошим качеством корпоративного управления ${ }^{13}$. Поэтому чем больше будет их доля, тем больший вес они будут иметь, что в результате скажется на эффективности в лучшую сторону;

- Увеличение доли менеджеров также увеличивает операционную эффективность, так как это позволяет избежать агентских конфликтов и повышает общие результаты компании.

Ключевой вывод из данного исследования - подтверждение гипотезы о влиянии качества корпоративного управления на операционную эффективность в целом. Значимая положительная связь была выявлена между индексом корпоративного управления и операционной эффективностью. Это хороший знак и знак того, что российским компаниям нужно продолжать совершенствовать качество корпоративного управления.

В заключение проанализируем, какой из четырех факторов, входящих в индекс корпоративного управления, имеет наибольшее влияние на операционную эффективность. Для этого проведем серию эконометрических тестов (см. Приложение 3), давая каждому фактору по очереди вес в 100\%. Результаты можно посмотреть в сводной таблице.

\footnotetext{
${ }^{13}$ http://lenta.ru/news/2011/06/03/kostin.
} 
Влияние отдельных блоков индекса корпоративного управления на операционную эффективность

\begin{tabular}{|c|c|c|}
\hline Фактор индекса CGI & Коэффициент & z-статистика \\
\hline Конфликт интересов & 0,328 & 2,64 \\
\hline $\begin{array}{l}\text { Обязанности } \\
\text { директоров }\end{array}$ & 0,5 & 3,34 \\
\hline Права акционеров & 0,69 & 3,93 \\
\hline Раскрытие информации & 0,54 & 5,23 \\
\hline
\end{tabular}

Данные результаты отражают то, какие элементы корпоративного управления имеют наибольший потенциал к увеличению операционной эффективности компаний, если к этим элементам относиться должным образом. Первым в списке элементов идет соблюдение прав акционеров. При повышении данного показателя на единицу эффективность вырастет на 0,69. Более слабое влияние на эффективность оказывают элементы раскрытия информации, обязанностей совета директоров и конфликта интересов в порядке уменьшения потенциала к улучшению операционной эффективности.

\section{Заключение}

В данной работе были рассмотрены результаты ряда исследований, посвященных выявлению связи между структурой собственности и операционной эффективностью компаний в разных странах, на основании которых были предложены гипотезы о влиянии качества корпоративного управления на операционную эффективность российских компаний. Операционная эффективность была оценена с помощью граничного метода DEA.

Чтобы преодолеть проблему изучения стилизованных фактов, авторами был предложен оригинальный индекс корпоративного управления и выявлены его элементы, имеющие наибольший потенциал к увеличению операционной эффективности компаний: соблюдение прав акционеров, раскрытие информации, обязанности совета директоров и предотвращение конфликтов акционеров (в порядке убывания по потенциалу).

На выборке из 54 российских крупнейших компаний за 2007 год было подтверждено четыре из шести гипотез, заявленных в исследовании. Таким образом, нам удалось доказать, что увеличение качества корпоративного управления, доли менеджеров, доли миноритариев и доли крупнейшего акционера, а также уменьшение доли совета директоров положительно влияет на операционную эффективность. Эффект увеличения доли государства остался неясным, несмотря на результаты многих авторов, где этот эффект был строго отрицательным.

Безусловно, это исследование можно и нужно развивать дальше путем выявления различий по отраслям и более подробного разделения на типы собственников. Увеличение выборки возможно с ростом количества прозрачных компаний, базирующихся в России. Все это оставляет простор для дальнейших исследований в области российского бизнеса.

\section{Список литературы}

1. Ananchotikul, N. (2007), Does Foreign Direct Investment Really Improve Corporate Governance? Evidence from Thailand. Working Paper, University of California, Berkley.

2. Black, B., Jang, H., Kim, W. (2005), Does Corporate Governance Predict Firms' Market Values? Evidence from Korea, European Corporate Governance Institute Finance Working Paper, 86.

3. Brown, D., Earle, J. (2000), Privatization and Restructuring in Russia: New Evidence from Panel Data on Industrial Enterprises, RECEP Working Paper, 1, 34.

4. Fethi, M., Jackson, P., Weyman-Jones, T. (2001), An Empirical Study of Stochastic DEA 
and Financial Performance: the Case of the Turkish Commercial Banking Industry, University of Leicester, Mimeo.

5. Frydman, R., Gray, Ch., Hessel, M., and Rapaczynski, A. (1997), Private Ownership and Corporate Performance: Some Lessons from Transition Economies, Economic Research Report, 9728.

6. Gompers, P., Ishii, J., Metrick, A., 2001, Corporate Governance and Equity Prices, NBER Working Paper, w8449.

7. Gumbau-Albert, M., Maudos, J. (1998), The Determinants of Efficiency: the Case of the Spanish Industry, Applied Economics, 34 (1998) 1941-1948.

8. Ivashkovskaya, I.V., Stepanova, A.N. (2011), Does strategic corporate performance depend on corporate financial architecture? Empirical study of European, Russian and other emerging market's firms, Journal of management and governance, 15(4) (2011) 603-616.

9. Khanna, T., Palepu, K., Kogan, J. (2002), Globalization and Corporate Governance Convergence? A Cross-Country Analysis, Working Paper, Harvard Business School.

10. Klapper, L., Love, I. (2002), Corporate Governance, Investor Protection, and Performance in Emerging Markets, World Bank Policy Research Working Paper, 2818.

11. Lazareva, O., Rachinskiy, A., Stepanov, S. (2007), A Survey of Corporate Governance in Russia, CEFIR/NES Working Paper series.

12. Liao, C.-S., Yang, C.-H., and Liu, D. (2010), Efficiency, productivity and ownership structure for securities firms in Taiwan, Journal of Money, Investment and Banking, 14 (2010) 46-58.

13. Paul, A. Gompers, J. L. Ishii, A. M. (2001), Corporate Governance and Equity Prices, NBER Working Paper, w8449.

14. Piesse, J. and Khatri, Y. (2002), Corporate Performance and Governance: A Stochastic Frontier Approach to Measuring and Explaining Inefficiency in the Malaysian Corporate Sector, International Review of Economics and Business, 49(2) (2002) 259-285.

15. Tirole, J. (2001), Corporate governance, Econometrica, 69 (1) (2001) 1-35.

16. Xu, X., Wang, Y. (1997), Ownership Structure, Corporate Governance, and Firm's Performance: The Case of Chinese Stock Companies, World Bank Working Paper, 1742 (1997) 27.

17. Williamson, O. (1984), Corporate Governance, Yale Law Journal, 93 (1984). 
Приложение 1. Оценки операционной эффективности с помощью метода DEA

\begin{tabular}{|c|c|}
\hline & Эффективность (DEA),\% \\
\hline «Седьмой континент» & 60,4 \\
\hline «Акрон» & 63,8 \\
\hline «Аэрофлот» & 100 \\
\hline «Автоваз» & 62,4 \\
\hline Аптеки «36,6» & 0,3 \\
\hline «Балтика» & 77,1 \\
\hline «Башинформсвязь» & 51 \\
\hline «Башкирэнерго» & 86,2 \\
\hline «Башнефть» & 92,8 \\
\hline «Центральный Телеком» & 49,7 \\
\hline «Челябинский Цинковый» & 79,1 \\
\hline «Евраз» & 100 \\
\hline «Эфес» & 83,1 \\
\hline «Комстар» & 51,6 \\
\hline «Дальневосточный Телеком» & 47,7 \\
\hline FESCO & 65 \\
\hline «Газ» & 86,3 \\
\hline «Газпром» & 100 \\
\hline Golden Telecom & 76,9 \\
\hline «Иркут» & 100 \\
\hline «Иркутскэнерго» & 77,8 \\
\hline Kalina & 85,5 \\
\hline «КамАЗ» & 99,5 \\
\hline «Казаньоргсинтез» & 82,3 \\
\hline «Красноярскэнерго» & 85,7 \\
\hline «Кубаньэнерго» & 83,1 \\
\hline «Кузбассэнерго» & 61,5 \\
\hline «Лебедянский» & 89,4 \\
\hline «Ленэнерго» & 70,5 \\
\hline «Лукойл» & 100 \\
\hline «Магнит» & 100 \\
\hline «Магнитогорсксталь» & 70,3 \\
\hline «Мечел» & 74,7 \\
\hline МГТС & 76,7 \\
\hline MTC & 87,1 \\
\hline «Нижнекамскнефтехим» & 100 \\
\hline «Норильский Никель» & 99,4 \\
\hline НОВАТЭК & 77,9 \\
\hline НЛМК & 100 \\
\hline «Полиметалл» & 70 \\
\hline «Полюс Золото» & 39,3 \\
\hline «Сан Инбев» & 93,4 \\
\hline «Северсталь» & 34,1 \\
\hline «Сургутнефтегаз» & 93,8 \\
\hline TNK-BP & 79,1 \\
\hline
\end{tabular}


Приложение 2. График сравнения тестов DEA и SFA

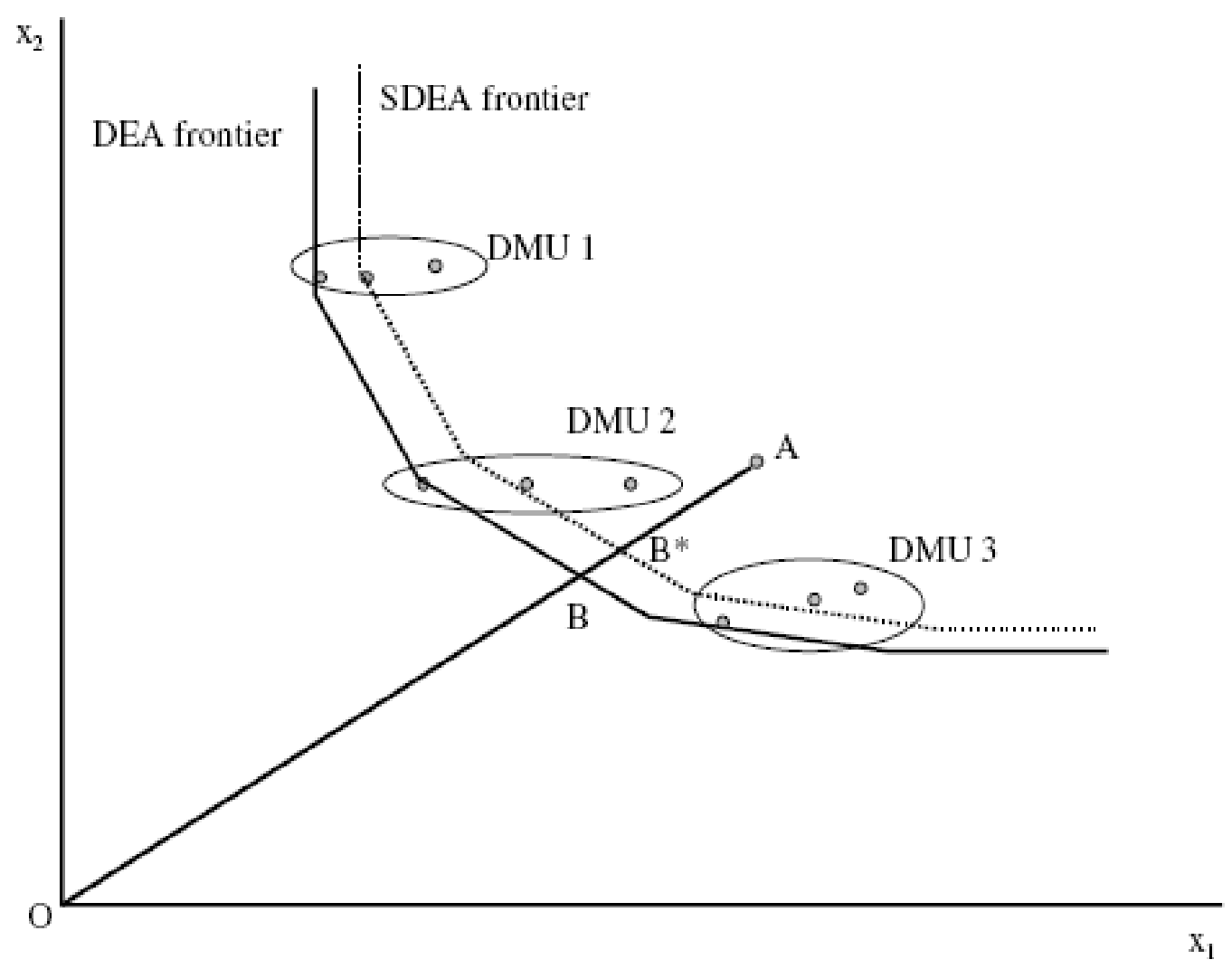




\section{Приложение 3. Результаты регрессионного анализа}

Приложение 3.1. Результаты EViews при построении Tobit-регрессии

Коэффициент Ст, ошибка z-статистика Вероятность

\begin{tabular}{crrrr}
\hline \hline BOD & $-0,432712$ & 0,267121 & $-1,619914$ & 0,0953 \\
CGI & 0,374357 & 0,135061 & 2,771757 & 0,0056 \\
GOV & 0,101928 & 0,143730 & 0,709157 & 0,4782 \\
MAN & 0,305619 & 0,145114 & 2,106054 & 0,0352 \\
MAXSHAR & 0,521760 & 0,144684 & 3,606205 & 0,0003 \\
MIN & 0,886220 & 0,259826 & 3,410826 & 0,0006 \\
\hline
\end{tabular}

Приложение 3.2. Результаты регрессии при идентифицировании потенциала элемента «конфликт интересов»

Коэффициент Ст, ошибка z-статистика Вероятность

\begin{tabular}{crrrr}
\hline \hline BOD & $-0,389479$ & 0,266730 & $-1,460196$ & 0,1442 \\
CGI & 0,328124 & 0,124069 & 2,644686 & 0,0082 \\
GOV & 0,112434 & 0,144333 & 0,778991 & 0,4360 \\
MAN & 0,259990 & 0,149959 & 1,733741 & 0,0830 \\
MAXSHAR & 0,518231 & 0,149009 & 3,477852 & 0,0005 \\
MIN & 0,894550 & 0,261551 & 3,420179 & 0,0006 \\
\hline \hline
\end{tabular}

Приложение 3.3. Результаты регрессии при идентифицировании потенциала элемента «обязанности совета директоров»

Коэффициент Ст, ошибка z-статистика Вероятность

\begin{tabular}{crrrr}
\hline \hline BOD & $-0,487632$ & 0,260692 & $-1,870529$ & 0,0614 \\
CGI & 0,503350 & 0,150790 & 3,338086 & 0,0008 \\
GOV & 0,026588 & 0,143012 & 0,185913 & 0,8525 \\
MAN & 0,244398 & 0,143716 & 1,700569 & 0,0890 \\
MAXSHAR & 0,523606 & 0,131981 & 3,967268 & 0,0001 \\
MIN & 0,902560 & 0,247540 & 3,646117 & 0,0003 \\
\hline \hline
\end{tabular}


Приложение 3.4. Результаты регрессии при идентифицировании потенциала элемента «права акционеров»

Коэффициент Ст, ошибка z-статистика Вероятность

\begin{tabular}{crrrr}
\hline \hline BOD & $-0,438351$ & 0,247848 & $-1,768630$ & 0,0770 \\
CGI & 0,693637 & 0,176311 & 3,934172 & 0,0001 \\
GOV & $-0,030002$ & 0,140736 & $-0,213181$ & 0,8312 \\
MAN & 0,185493 & 0,141606 & 1,309926 & 0,1902 \\
MAXSHAR & 0,313974 & 0,157173 & 1,997630 & 0,0458 \\
MIN & 0,656426 & 0,257551 & 2,548726 & 0,0108 \\
\hline \hline
\end{tabular}

Приложение 3.5. Результаты регрессии при идентифицировании потенциала элемента «раскрытие информации»

Коэффициент Ст, ошибка Z-статистика Вероятность

\begin{tabular}{crrrr}
\hline \hline BOD & $-0,419136$ & 0,225428 & $-1,859285$ & 0,0630 \\
CGI & 0,547213 & 0,104549 & 5,234052 & 0,0000 \\
GOV & $-0,038307$ & 0,126889 & $-0,301892$ & 0,7627 \\
MAN & 0,156538 & 0,128790 & 1,215452 & 0,2242 \\
MAXSHAR & 0,258931 & 0,137264 & 1,886375 & 0,0592 \\
MIN & 0,487367 & 0,241858 & 2,015095 & 0,0439 \\
\hline \hline
\end{tabular}




\section{Приложение 4.1. Структура индекса корпоративного управления по российским компаниям}

\begin{tabular}{|c|c|c|c|c|}
\hline Номер & Bonрocы & Правило подсчёта & Максимальное количество очков & $\mathrm{Bec}$ \\
\hline & А. Конфликт интересов & & 6 & $40 \%$ \\
\hline a1 & Является ли председатель совета директоров одним человеком с СЕО? & 1, если а1=нет, иначе - 0 & 1 & \\
\hline a2 & Является ли председатель совета директоров независимым? & 1, если а2=да, иначе - 0 & 1 & \\
\hline a3 & Существует ли в компании ревизионная комиссия? & 1, если а3=да, иначе - 0 & 1 & \\
\hline a4 & Существует ли в компании комитет по вознаграждениям? & 1, если а4=да, иначе - 0 & 1 & \\
\hline a5 & Существует ли в компании комитет по назначениям? & 1, если а5=да, иначе - 0 & 1 & \\
\hline \multirow[t]{2}{*}{ a6 } & Существует ли в компании комитет по корпоративному управлению? & 1, если а6=да, иначе - 0 & 1 & \\
\hline & Б. Обязанности совета директоров. & & 5 & $20 \%$ \\
\hline 61 & Количество ежегодных собраний совета директоров. & 1, если $61>4$, иначе - 0 & 1 & \\
\hline 62 & Существует ли собрание только для независимых директоров? & 1, если б2=да, иначе - 0 & 1 & \\
\hline 63 & Количество ежегодных собраний ревизионной комиссии. & 1, если б3>4, иначе - 0 & 1 & \\
\hline 64 & Чётко ли компания происывает роли и задачи совета директоров? & 1, если б4=да, иначе - 0 & 1 & \\
\hline \multirow[t]{2}{*}{65} & Были ли санкции по отношению к совету директоров в последние 2 года? & 1, если 65=нет, иначе - 0 & 1 & \\
\hline & В. Права акционеров. & & 5 & $10 \%$ \\
\hline B1 & Собирает ли компание ежегодное собрание акционеров? & 1, если в1=да, иначе - 0 & 1 & \\
\hline $\mathrm{B} 2$ & Использует ли компания правило 1 акция - 1 голос? & 1, если в2=да, иначе - 0 & 1 & \\
\hline B3 & Разрешено ли удаленное голосование? & 1, если в3=да, иначе - 0 & 1 & \\
\hline B4 & Раскрывает ли компания дивидендную политику? & 1, если в4=да, иначе - 0 & 1 & \\
\hline \multirow[t]{2}{*}{ B5 } & Приводит ли компания объяснение уровню своих дивидендных выплат? & 1, если в5=да, иначе - 0 & 1 & \\
\hline & Г. Раскрытие информации. & & 7 & $20 \%$ \\
\hline r1 & Раскрывает ли компания степень посещаемости совета директоров? & 1, если г1=да, иначе - 0 & 1 & \\
\hline$\ulcorner 2$ & Раскрывает ли компания уровень компенсации директоров? & 1, если г2=да, иначе - 0 & 1 & \\
\hline r3 & Раскрывает ли компания долю акций директоров? & 1, если г3=да, иначе -0 & 1 & \\
\hline r4 & Раскрывает ли компания долю акций менеджмента? & 1, если г4=да, иначе - 0 & 1 & \\
\hline r5 & Раскрывает ли компания свою корпоративную структуру? & 1, если г5=да, иначе - 0 & 1 & \\
\hline r6 & Существует ли в компании отдел по взаимоотношению с инвесторами? & 1, если г6=да, иначе - 0 & 1 & \\
\hline 「7 & Публикует ли компания годовую отчетность? & 1, если г7=да, иначе - 0 & 1 & \\
\hline
\end{tabular}




\section{Приложение 4.2. Индекс корпоративного управления}

\begin{tabular}{|c|c|c|c|c|c|c|c|c|c|c|c|c|c|c|c|c|c|c|c|c|c|c|c|}
\hline \multirow[t]{3}{*}{$\mathrm{Bec}$} & \multicolumn{6}{|c|}{0,4} & \multicolumn{5}{|c|}{0,2} & \multicolumn{5}{|c|}{0,1} & \multicolumn{7}{|c|}{0,2} \\
\hline & \multicolumn{6}{|c|}{ Конфликт интересов } & \multicolumn{5}{|c|}{ Обязанности совета директоров } & \multicolumn{5}{|c|}{ Права акционеров } & \multicolumn{7}{|c|}{ Раскрытие информации } \\
\hline & a1 & $\mathrm{a} 2$ & a3 & a4 & a5 & a6 & 61 & 62 & 63 & 64 & 65 & B1 & $B 2$ & B3 & B4 & B5 & r1 & 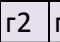 & \begin{tabular}{|l|l|}
$r 3$ & 4
\end{tabular} & \begin{tabular}{|l|l}
44 & 1
\end{tabular} & \begin{tabular}{|l|l}
$\mathrm{r} 5$ & $\mathrm{r}$
\end{tabular} & r6 & $r 7$ \\
\hline 7th continent & 0 & 1 & 0 & 0 & 1 & 0 & 0 & 0 & 0 & 0 & 1 & 1 & 1 & 1 & 0 & 0 & 0 & 0 & 1 & 1 & 0 & 1 & 1 \\
\hline Acron & 1 & 1 & 1 & 0 & 1 & 0 & 0 & 0 & 1 & 0 & 1 & 1 & 1 & 1 & 1 & 1 & 1 & 0 & 1 & 1 & 1 & 1 & 1 \\
\hline Aeroflot & 1 & 0 & 1 & 1 & 1 & 1 & 1 & 0 & 1 & 1 & 1 & 1 & 0 & 1 & 1 & 1 & 1 & 1 & 1 & 1 & 1 & 1 & 1 \\
\hline Avtovaz & 0 & 0 & 1 & 1 & 1 & 1 & 1 & 0 & 1 & 1 & 1 & 1 & 0 & 1 & 0 & 0 & 0 & 0 & 1 & 1 & 1 & 1 & 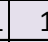 \\
\hline Apteka 36.6 & 1 & 1 & 0 & 0 & 1 & 0 & 0 & 0 & 0 & 1 & 1 & 1 & 1 & 1 & 0 & 0 & 0 & 0 & 1 & 1 & 0 & 1 & 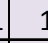 \\
\hline Baltika & 1 & 0 & 1 & 1 & 1 & 0 & 1 & 0 & 1 & 1 & 1 & 1 & 1 & 1 & 1 & 0 & 0 & 0 & 1 & 1 & 1 & 1 & 1 \\
\hline Bashinformsvyaz & 0 & 0 & 1 & 1 & 1 & 0 & 0 & 0 & 1 & 0 & 1 & 1 & 1 & 1 & 1 & 0 & 0 & 0 & 1 & 1 & 1 & 1 & t \\
\hline Bashkirenergo & 1 & 0 & 0 & 0 & 1 & 0 & 0 & 0 & 0 & 0 & 1 & 1 & 0 & 1 & 0 & 0 & 0 & 0 & 1 & 1 & 1 & 1 & 1 \\
\hline Bashneft & 1 & 0 & 1 & 1 & 1 & 0 & 0 & 0 & 1 & 1 & 1 & 1 & 0 & 1 & 1 & 1 & 1 & 0 & 1 & 1 & 1 & 1 & 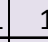 \\
\hline Central Telekom & 0 & 1 & 1 & 1 & 1 & 0 & 0 & 0 & 1 & 0 & 1 & 1 & 1 & 1 & 1 & 0 & 0 & 0 & 1 & 1 & 1 & 1 & 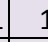 \\
\hline Chelyabinsky Zinkovyj & 0 & 1 & 0 & 0 & 1 & 0 & 0 & 0 & 0 & 1 & 1 & 1 & 0 & 1 & 0 & 0 & 0 & 0 & 1 & 1 & 1 & 1 & 1 \\
\hline Evraz Group & 1 & 1 & 1 & 1 & 1 & 1 & 1 & 0 & 1 & 1 & 1 & 1 & 0 & 1 & 1 & 1 & 1 & 1 & 1 & 1 & 1 & 1 & 1 \\
\hline Efes & 1 & 1 & 0 & 0 & 1 & 0 & 0 & 0 & 0 & 0 & 1 & 1 & 0 & 1 & 0 & 0 & 0 & 0 & 1 & 1 & 0 & 1 & 1 \\
\hline Comstar-UTS & 1 & 1 & 1 & 1 & 1 & 0 & 0 & 0 & 1 & 1 & 1 & 1 & 1 & 1 & 0 & 0 & 0 & 0 & 1 & 1 & 0 & 1 & 1 \\
\hline Far Eastern Telekom & 0 & 0 & 1 & 0 & 1 & 0 & 0 & 0 & 1 & 1 & 1 & 1 & 1 & 1 & 1 & 0 & 0 & 0 & 1 & 1 & 0 & 1 & 1 \\
\hline FESCO & 1 & 0 & 0 & 1 & 1 & 0 & 0 & 0 & 0 & 0 & 1 & 1 & 1 & 1 & 0 & 0 & 0 & 0 & 1 & 1 & 0 & 1 & 1 \\
\hline GAZ & 0 & 0 & 0 & 1 & 1 & 0 & 0 & 0 & 0 & 1 & 1 & 1 & 1 & 1 & 0 & 0 & 0 & 0 & 1 & 1 & 0 & 1 & \\
\hline Gazprom & 1 & 1 & 1 & 1 & 1 & 1 & 1 & 0 & 1 & 1 & 1 & 1 & 0 & 1 & 1 & 1 & 1 & 1 & 1 & 1 & 1 & 1 & -1 \\
\hline Golden telecom & 1 & 0 & 0 & 0 & 1 & 0 & 0 & 0 & 0 & 1 & 1 & 1 & 0 & 1 & 0 & 0 & 0 & 0 & 1 & 1 & 1 & 1 & 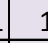 \\
\hline Irkut & 1 & 0 & 0 & 1 & 1 & 1 & 1 & 0 & 1 & 1 & 1 & 1 & 0 & 1 & 1 & 1 & 1 & 0 & 1 & 1 & 1 & 1 & - \\
\hline Irkutskenergo & 1 & 0 & 0 & 0 & 1 & 0 & 0 & 0 & 0 & 1 & 1 & 1 & 1 & 1 & 1 & 0 & 0 & 0 & 1 & 1 & 0 & 1 & 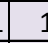 \\
\hline Kalina & 0 & 1 & 0 & 0 & 1 & 0 & 0 & 0 & 0 & 0 & 1 & 1 & 1 & 1 & 0 & 0 & 1 & 0 & 1 & 1 & 1 & 1 & 1 \\
\hline Kamaz & 1 & 0 & 0 & 0 & 1 & 0 & 1 & 0 & 0 & 1 & 1 & 1 & 1 & 1 & 0 & 0 & 0 & 0 & 1 & 1 & 0 & 1 & 1 \\
\hline Kazanorgsintez & 1 & 0 & 0 & 0 & 1 & 0 & 0 & 0 & 0 & 1 & 1 & 1 & 0 & 1 & 1 & 1 & 1 & 0 & 1 & 1 & 0 & 1 & 1 \\
\hline Krasnoyarskenergo & 1 & 0 & 1 & 0 & 1 & 0 & 1 & 0 & 0 & 1 & 1 & 1 & 0 & 1 & 1 & 0 & 0 & 0 & 1 & 1 & 0 & 1 & 1 \\
\hline Kubanenergo & 1 & 0 & 1 & 1 & 1 & 0 & 1 & 0 & 0 & 1 & 1 & 1 & 1 & 1 & 1 & 0 & 0 & 0 & 1 & 1 & 0 & 1 & 1 \\
\hline Kuzbassenergo & 1 & 0 & 1 & 1 & 1 & 0 & 1 & 0 & 0 & 1 & 1 & 1 & 0 & 1 & 1 & 0 & 0 & 0 & 1 & 1 & 0 & 1 & - \\
\hline Lebedyansky & 0 & 1 & 1 & 1 & 1 & 0 & 0 & 0 & 0 & 0 & 1 & 1 & 1 & 1 & 0 & 0 & 0 & 0 & 1 & 1 & 1 & 1 & 1 \\
\hline Lenenergo & 1 & 0 & 1 & 1 & 1 & 0 & 1 & 0 & 0 & 1 & 1 & 1 & 1 & 1 & 1 & 0 & 0 & 0 & 1 & 1 & 1 & 1 & 1 \\
\hline LUKoil & 1 & 1 & 1 & 1 & 1 & 1 & 1 & 0 & 1 & 1 & 1 & 1 & 0 & 1 & 1 & 1 & 1 & 1 & 1 & 1 & 1 & 1 & 1 \\
\hline Magnit & 1 & 0 & 0 & 0 & 1 & 0 & 0 & 0 & 0 & 1 & 1 & 1 & 1 & 1 & 1 & 0 & 0 & 0 & 1 & 1 & 1 & 1 & 1 \\
\hline Magnitogorsk Stee & 1 & 0 & 1 & 1 & 1 & 1 & 1 & 0 & 1 & 1 & 1 & 1 & 0 & 1 & 1 & 1 & 1 & 0 & 1 & 1 & 1 & 1 & 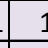 \\
\hline Mechel & 1 & 0 & 1 & 1 & 1 & 1 & 1 & 0 & 1 & 1 & 1 & 1 & 0 & 1 & 1 & 1 & 1 & 0 & 1 & 1 & 1 & 1 & 1 \\
\hline MGTS & 1 & 0 & 1 & 0 & 1 & 0 & 1 & 0 & 0 & 1 & 1 & 1 & 1 & 1 & 1 & 0 & 0 & 0 & 1 & 1 & 1 & 1 & 1 \\
\hline MTS & 1 & 1 & 1 & 1 & 1 & 1 & 1 & 0 & 1 & 1 & 1 & 1 & 0 & 1 & 1 & 1 & 0 & 0 & 1 & 1 & 1 & 1 & 1 \\
\hline Nizhnekamskneftekhim & 1 & 0 & 1 & 1 & 1 & 0 & 0 & 0 & 0 & 1 & 1 & 1 & 0 & 1 & 1 & 0 & 0 & 0 & 1 & 1 & 0 & 1 & 1 \\
\hline Norilsk Nickel & 1 & 0 & 1 & 1 & 1 & 1 & 1 & 0 & 1 & 1 & 1 & 1 & 0 & 1 & 1 & 1 & 1 & 1 & 1 & 1 & 1 & 1 & 1 \\
\hline NOVATEK & 1 & 0 & 1 & 1 & 1 & 0 & 0 & 0 & 0 & 1 & 1 & 1 & 0 & 1 & 1 & 1 & 0 & 0 & 1 & 1 & 1 & 1 & 1 \\
\hline NLMK & 1 & 1 & 1 & 1 & 1 & 1 & 1 & 0 & 1 & 1 & 1 & 1 & 0 & 1 & 1 & 1 & 1 & 1 & 1 & 1 & 1 & 1 & 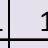 \\
\hline Polimetall & 1 & 0 & 1 & 1 & 1 & 1 & 0 & 0 & 1 & 1 & 1 & 1 & 0 & 1 & 1 & 0 & 1 & 0 & 1 & 1 & 0 & 1 & 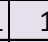 \\
\hline Polus Gold & 1 & 0 & 1 & 1 & 1 & 1 & 1 & 0 & 1 & 1 & 1 & 1 & 0 & 1 & 1 & 0 & 0 & 0 & 1 & 1 & 1 & 1 & 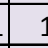 \\
\hline Sun inbev & 1 & 1 & 0 & 0 & 1 & 0 & 0 & 0 & 0 & 1 & 1 & 1 & 1 & 1 & 1 & 0 & 0 & 0 & 1 & 1 & 0 & 1 & 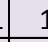 \\
\hline Severstal & 1 & 1 & 1 & 1 & 1 & 1 & 1 & 0 & 1 & 1 & 1 & 1 & 0 & 1 & 1 & 1 & 1 & 0 & 1 & 1 & 1 & 1 & 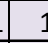 \\
\hline Surgutneftegaz & 1 & 0 & 1 & 1 & 1 & 1 & 1 & 0 & 1 & 1 & 1 & 1 & 0 & 1 & 1 & 1 & 1 & 1 & 1 & 1 & 1 & 1 & 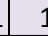 \\
\hline TNK-BP & 1 & 1 & 1 & 1 & 1 & 1 & 1 & 0 & 1 & 1 & 1 & 1 & 0 & 1 & 1 & 1 & 1 & 1 & 1 & 1 & 1 & 1 & \\
\hline
\end{tabular}

